Case Report

iMedPub Journals

www.imedpub.com

\section{Unilateral Re-expansions Pulmonary Edema after Thoracic Drainage Insertion in Patient with Extensive Para-pneumonic Pleural Effusion}

\section{Abstract}

In presence of extensive pleural effusion, there is usually a largely atelectatic lung. After thoracic drainage insertion and immediate expansion of the lung, there is a risk of re-expansion pulmonary edema. The following case, described as a rare, life-threatening complication, describes the development of a pulmonary edema after insertion of a chest tube in a completely atelectatic lung as a result of compression due to large pleural effusion.

Keywords: Pulmonary edema; Atelectatic lung; Pleural effusion; Thoracic

Received: May 16, 2018; Accepted: May 21, 2018; Published: May 28, 2018

\section{Case Report}

A 24-year-old patient with tetraparesis presented herself in the Emergency Department of our Hospital with dyspnea and fever of $38.9^{\circ} \mathrm{C}$ late in the evening.

\section{Clinical, Laboratory and Radiological Values}

The laboratory chemistry showed increased infection parameters of leucocytes $38.7 / \mathrm{hl}$ and CRP of $31.8 \mathrm{mg} / \mathrm{dl}$.

In X-ray of thorax total shading on left. When empyema was suspected, a chest CT scan was performed with a complete left atelectatic lung and extensive pleura effusion (Figures $\mathbf{1 a}$ and $\mathbf{1 b}$ ).

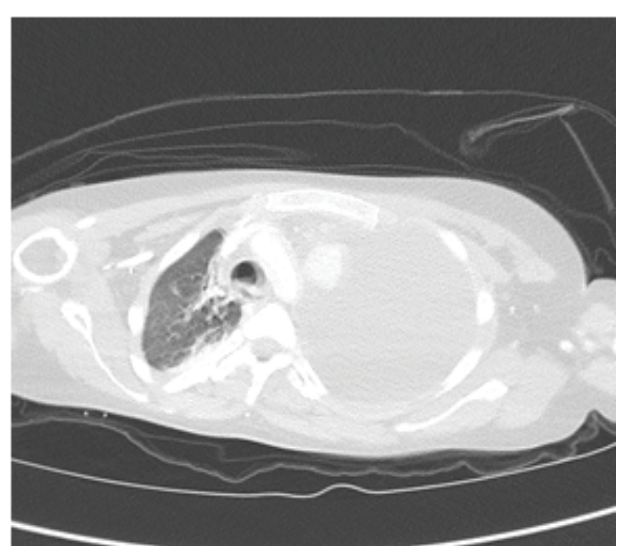

Figure 1a Preoperative chest $\mathrm{CT}$, with pronounced effusion / empyema on left.
Mohammed Ibrahim ${ }^{1 *}$, Norbert Friedel ${ }^{1}$, Christoph Erdmann ${ }^{1}$, Claus Steppert ${ }^{2}$ and Bernd Linsmeier ${ }^{1 *}$

1 Department of Cardiothoracic Surgery, Bayreuth Hospital, Bavaria, Germany

2 Clinic of Pulmonology, Thoracic Oncology, Sleep and Respiratory Medicine, Bayreuth Hospital, Bavaria, Germany

Corresponding author:

Mohammed Ibrahim, Bernd Linsmeier

झ mohammed.ibrahim@klinikum-bayreuth. de, thoraxhirurgie@klinikum-bayreuth.de

Department of Cardiothoracic Surgery, Bayreuth Hospital, Bavaria, Germany.

Tel: $0921400-5902$

Citation: Ibrahim M, Friedel N, Erdmann C, Steppert C, Linsmeier B (2018) Unilateral Reexpansions Pulmonary Edema after Thoracic Drainage Insertion in Patient with Extensive Para-pneumonic Pleural Effusion. J Univer Surg. Vol.6 No.2:13

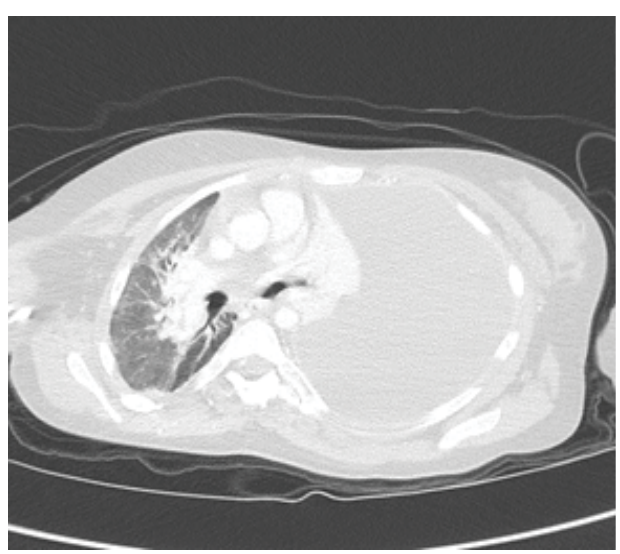

Figure 1b Preoperative CT chest, with evidence of relative complete atelectasis of the left lung. 


\section{Therapy}

As therapy, the immediate insertion of a $24 \mathrm{CH}$ chest tube in local anesthesia in the $6^{\text {th }}$ ICR was performed in the middle axillary line with an initial suction of $-20 \mathrm{~cm} \mathrm{H}_{2} \mathrm{O}$. It spontaneously deflated nearly $950 \mathrm{ml}$ of putrid secretions (Figure 2).

\section{Follow}

The X-ray chest radiograph after chest tube insertion showed fully extended lungs on both sides without evidence of pneumothorax and correct location of chest tube. In the first $24 \mathrm{~h}$, the drainage pumped about $2000 \mathrm{ml}$ purulent secretions.

After $24 \mathrm{~h}$, the condition worsened and the patient complained of increased dyspnoea, tachypnoea, tachycardia, respiratory insufficiency, with necessary for intubation and mechanical ventilation. The X-ray thorax follow-up showed a pronounced ipsilateral (left) shadow. Thoracic drainage was open and not stenotic with fibrin or old blood coagulation; bronchoscopic revealed a few mucous secretions endobronchially left. This confirmed the diagnosis of the full image of re-expansion pulmonary edema (Figure 3 ).

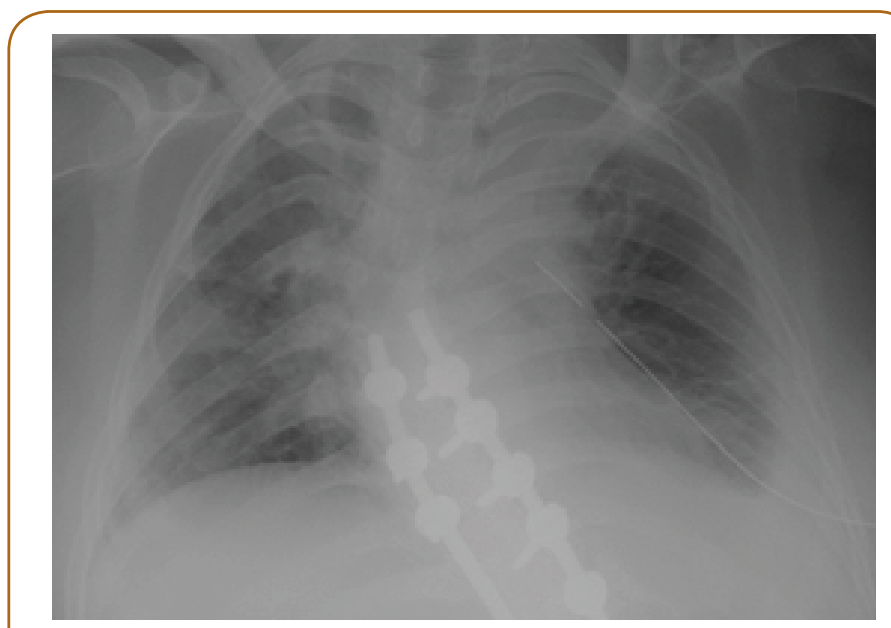

Figure 2 Ventilated lung left after the chest drainage system insertion.

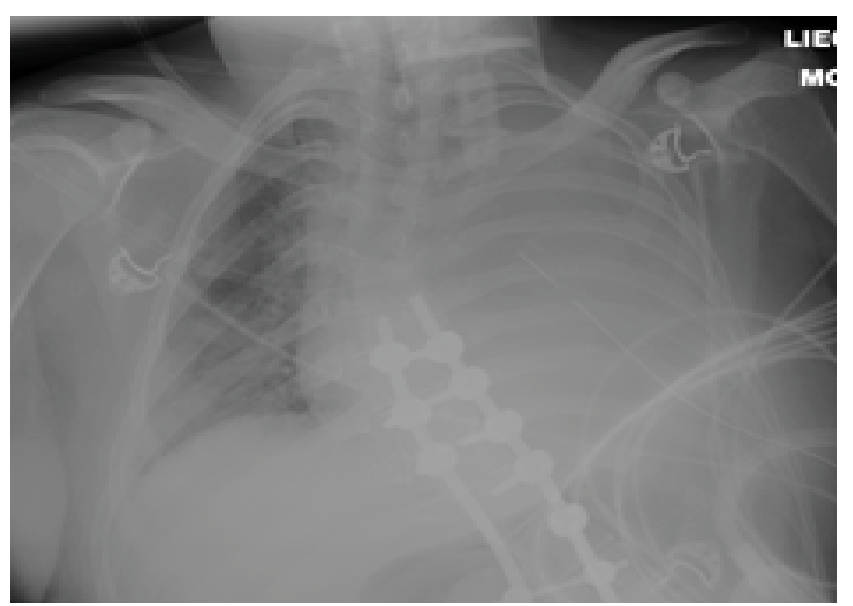

Figure 3 Clear evidence of re-expansion pulmonary edema left sides within 24 hours of chest drainage system insertion.

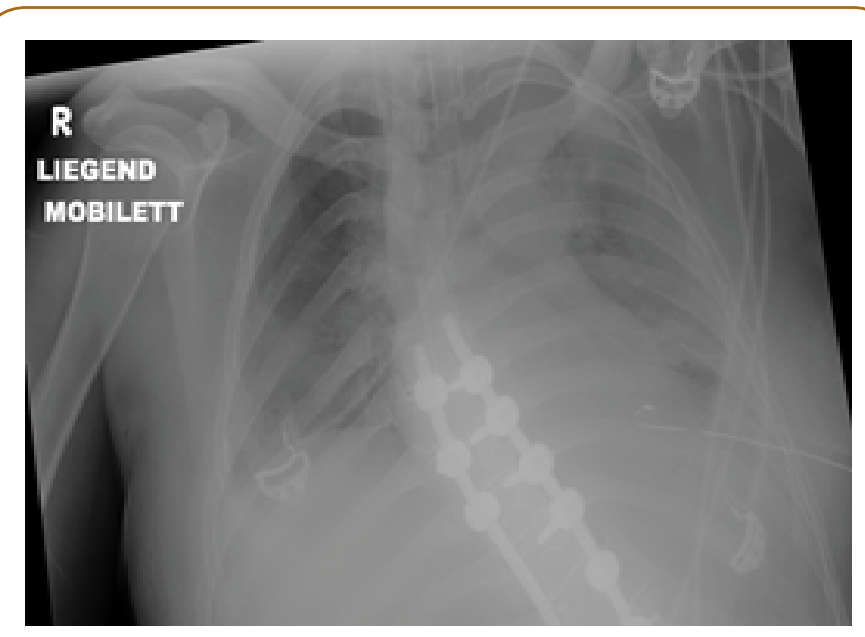

Figure 4 Significant restored shadowing on the left (pulmonary edema) after CPAP due to ventilation, antibiotics, diuretics and cortisone therapy.

The weight-adapted administration of prednisolone, mechanical ventilation, PEEP of 7 , a $\mathrm{FiO}_{2}$ of $45 \%$ and diuretic therapy showed a significant improvement in the generalized status of the patient.

The X-ray done on the following day showed a complete extended lung with significantly declining shadowing without infiltration (Figure 4).

After stabilization of the patient's condition, an operation has been done, as VATS (Video Assisted ThoracoScopy) left sides with decortication. Because of further respiratory insufficiency it has been performed a plastic tracheotomy.

\section{Discussion}

The occurrence of re-edema is a rarity $(<1 \%)$, although in some international literature it has been described in some case reports.

Unilateral re-expansive edema is described as a rare complication in pneumothoracic therapy as well as in the treatment of extensive pleural effusion, with a lethality of up to $20 \%$ [1].

The clinical and radiographic manifestations vary from a pale radiographic finding with an asymptomatic patient to a fulminant course with respiratory insufficiency and shock symptoms. Main risk factors are:

- Young patient age.

- Larger and longer existing pneumothorax (>24 h).

- Relative total lung atelectasis pleura effusion or empyema-related compression.

- Rapid re-expansion of the lungs.

In case of fulminant progressions as in the case described; however, invasive or non-invasive CPAP ventilation may become necessary.

With a corresponding risk profile, it is recommended for 
prophylaxis to prevent the direct connection of the thoracic drainage to the suction pump with high suction negative $-20 \mathrm{~cm}$ $\mathrm{H}_{2} \mathrm{O}$ pressure and to initially use only the bottle water system drainage unit or connection to suction pump with physiological weak pressure $-8 \mathrm{~cm} \mathrm{H}_{2} \mathrm{O}$. This can ensure a slower re-expansion of the lung [2].

\section{Conclusion}

Although there are no major studies on the risk factors and on the management of extensive pneumothorax or increased effusion, empirical evidence suggests that relieving the pleura of

\section{References}

1 Schmidt-Horlohé N, Azvedo CT, Rudig L, Habekost M (2008) Fulminant unilateral pulmonary edema after insertion of a chest more than two liters of air or effusion significantly increases the risks of re-expansion lung edema.

Re-pulmonary edema is a non-cardiac unilateral pulmonary edema observed after treatment of pneumothorax or after drainage of large-volume pleural effusions.

Pathogenesis is unclear, most likely a permeability pulmonary edema in which as micro vascular injury occurs due to mechanical stress associated with lung expansion (capillary leaks).

\section{Conflict of Interest}

The authors declare that there is conflict of interest.

tube: A complication after a primary spontaneous pneumothorax. Dtsch Arztebl Int 105: 878-881.

2 Huber LC, Wieser S (2013) Re-expansion lung edema. Schweiz Med Forum 13: 349-350. 